\title{
Training sessions for postgraduates to pass the English exam
}

\author{
Alexander Kabanov ${ }^{1}$, Nelly Savelyeva ${ }^{1,{ }^{*}}$, Natalie Nevraeva ${ }^{1}$, Anna Vostretsova $^{1}$, Elena \\ Grishina $^{1}$, and Tatiana Makarova ${ }^{2}$ \\ ${ }^{1}$ Ural Federal University, Ekaterinburg, Russia \\ ${ }^{2}$ Ural State Agrarian University, Ekaterinburg, Russia
}

\begin{abstract}
Foreign language is a mandatory subject at all stages of higher education - from bachelors to doctoral studies. Knowledge of a foreign language at the present stage of development of science and technology is a very important skill for expanding the exchange of scientific ideas. It is impossible to conduct research in a single country without using world experience. Even with advanced technologies that no one else owns, scientists are forced to study the world's experience in different fields of activity in order to develop them. Any sphere of human activity involves various developments, so all Sciences are interconnected. Training of young scientists in various fields of science is also based on communication. Without a language, both native and foreign, it is impossible to communicate and understand the subject of study. Reading scientific articles in a foreign language requires knowledge of language grammar and terminology, but as for scientists, this terminology should be narrowly focused. There can be no ambiguity or different interpretations. On the other hand, if we take English words as an example, most of them are polysemantic. Accordingly, it is necessary to operate with the meaning that is applicable in a specific area of use of the term.
\end{abstract}

\section{Introduction}

Modern young people have already begun to realize that the knowledge of a foreign language expands the scope of understanding of people and allows them to meet their needs in communication, obtaining information, and thereby increase their wages, which in turn improves the quality of life [3, 7]. Therefore, most graduate students already have a fairly good level of proficiency in a foreign language and their main goal in preparing for the exam is to develop the ability to understand and translate authentic texts in their specialty, namely, the possession of terminology, the use of the desired meaning of a word in a particular context [1].

Despite the fact that people enter graduate school consciously, unlike undergraduate students, where it is not uncommon to need only a higher education diploma, however, you can often encounter certain difficulties in their preparation.

\footnotetext{
Corresponding author: nellik1983@mail.ru
} 
Graduate students are adults. They already have higher education and basic skills. They may mistakenly believe that these skills are sufficient for passing exams in graduate school. Therefore, many of them believe that attending classes in a foreign language is not a mandatory part of training. Moreover, having a family and children distracts most of their attention from their studies, and the need to work exhausts, reduces the attention and speed of perception of educational material. Writing a dissertation is the main goal that they set for themselves, spending most of their academic time on it, respectively, ordinary academic subjects are held on the principle of "by the way" [6].

\section{Results and Discussion}

As for preparation for exams in a foreign language, both for admission to graduate school and at the end of it, it is carried out mainly independently, with rare attendance in the classroom. Nevertheless, there are opportunities to train students at the proper level and taking into account modern realities, which are such that a graduate student needs to get knowledge, and he is even willing to spend time on it, but this time does not exactly coincide with the proposals of University $[2,4]$. For example, due to employment, a graduate student can study on a Saturday evening, while the University schedule assumes classes only on working days, at best on Saturday morning. If you allocate all the time of classroom sessions for individual consultations, it will not be enough to pay attention to all students, because academic groups can be quite large. The lecturer will have to spend much more time and go beyond the academic hours provided for in the curriculum.

Therefore, it is necessary to correlate the interests of postgraduates and the University's capabilities, try to combine everything and everyone on a common learning platform, combining classroom and distance learning technologies and thereby give students the opportunity to choose the path by which they will achieve their goal - to engage with a teacher, independently, or combine separate stages of training.

So, the skills that a graduate student of non-linguistic specialties must show on the foreign language exam are as follows:

- working with a dictionary;

- understanding the main content of the authentic text in the specialty;

- interpretation and translation;

- conversational skills; maintaining conversation.

To solve the described problems of organizing classes among postgraduates, we offer the following models:

1. Traditional model.

The traditional model is classroom classes in an academic group, which at the postgraduate stage consists of students of different ages and different initial training (although the previous stages of training-school, bachelor's and master's degrees already assume that the basic level of knowledge of a foreign language is already there, the attitude to the learning process on the part of both students and teachers can provoke a large difference in the level of knowledge). However, even if there are gaps in some basic level topics, there is no need to explain the training material in full to everyone.

It is enough to identify the main aspects, difficult cases of using certain language constructions and offer material for self-study, followed by answers to questions and analysis of particularly difficult and not typical cases. The main time of classes should be spent on developing certain skills in a foreign language, which must be shown on the exam, or training and improving existing skills, but in a narrower scientific direction.

Auditory classes in the academic group remain the traditional organization of teaching at the University. But modern trends are such that this form is becoming less effective, since it involuntarily makes everyone perceive everything in a row, without the possibility of choice. 
At the same time, educational time is spent on the perception of information that is not needed (for example, a graduate student knows a topic in grammar, but is forced to listen to it again, because someone in the group does not understand it well, and may miss aspects that are really necessary for him).

At the stage of postgraduate study, not the same level of knowledge is especially noticeable, since different ages, the speed of learning of educational material. This level of initial training does not have the desired effect in explaining "everything to everyone" [8]. If you follow some logic that you need to focus on "strong students, and weak ones to catch up", then there is a probability that a student with an insufficient level of knowledge at a certain stage may miss something (distracted, missed classes, etc.) and this fact will provoke another gap, and weak knowledge will aggravate the situation. It may also happen that this gap will not give a proper understanding of the subsequent material and all training will become ineffective, and even useless.

If we focus on a student with an average level of basic training, in this case, graduate students with a high level of knowledge of a foreign language will simply have nothing to do in the classroom. In this case the training will become useless for a part of the academic group.

Also, in some universities, there is a practice of organizing groups of initial training, but in this case, it becomes unclear the entire result of the previous stages. There were tests and assessments that must correspond to the level of knowledge provided by the state standard and curriculum. Therefore, this practice of organizing classes is not even worth considering.

However, when organizing training in the classroom, it is possible to increase the effectiveness of classes and attract the attention of most students. To do this, it is necessary to reorganize the training process so that it meets the requirements of all categories of students in the course. It is advisable to present all the necessary requirements at once and indicate the final result to be achieved.

In particular, we define the goals of each of the training stages and formulate what you need to have at the end of the course, for example, one of the intermediate goals is the ability to freely parse a complex sentence with subsequent translation.

This type of task has the following stages: finding the predicate and analyzing its composition, which requires knowledge about modal and auxiliary verbs, personal verb endings, sentence structure, word order, etc., determining the predicate's mood, voice and time.

- Finding the subject and determining the parts of speech that make up it. To do this, you need to know the parts of speech that can act as a subject, determine the form that allows a particular part of speech to be the main member of the sentence (the nominative case of a noun in Russian, a noun without a preposition in English, etc.), as well as words that relate to the subject (definitions, additions in verb forms, etc.).

- $\quad$ Finding secondary members of a sentence, determining the parts of speech that Express them, and the words and phrases that relate to them.

- Identifying grammatical structures and phenomena that are not found in the Russian language (there + be, gerund, infinitive as a definition, etc.) and determining how to translate them.

- Finding the right and left definitions at each of the previous stages, and again how to translate them.

- Identifying other grammatical constructions in the sentence (introductory words. Interjections, etc.).

To achieve this goal, each of the graduate students can follow their own path, comprehending exactly what is necessary, in which there is some misunderstanding. So. some of them, knowing grammatical phenomena, develop skills for understanding a complex sentence, while others eliminate gaps that hinder the achievement of the goal. The less 
knowledge, the more intensive the learning process should be, the more questions should be formulated. Some of these issues should be solved by the graduate student himself, using the help of educational materials, and some of them should be discussed with the lecturer through individual consultations in the classroom.

The role of the teacher in this learning model is as follows:

- Ensure that the training material required for the course is available. Although with the development of the Internet and electronic libraries, any necessary training material can be found by the student himself, nevertheless, it is advisable to present the theory in the form of a brief summary that would allow you to quickly recall the previously studied rules. Here you need to give links to more detailed information, if suddenly a summary is not enough, and also provide a list of educational literature for a full study of the necessary section if necessary.

- Monitor the learning process and correct mistakes made at a certain stage. The lecturer gives individual advice to the graduate student on difficult and incomprehensible moments in training. If there is an understanding of the topic under discussion, then there is no need to spend time studying it. By providing short answers and providing sources of knowledge for detailed study, we can solve problems faster and cover a wider range of topics.

- $\quad$ Test the learner's knowledge and acquired skills in practice. Here it is advisable to use such methods of checking skills that you want to use on the exam. In particular, if the exam involves translating the text of an authentic scientific article, then the control should be carried out on the basis of the scientific text.

Special attention should be paid to working with the dictionary, which at the present stage is quite a big problem. Electronic translation tools, electronic dictionaries, which are now widely used by students at different stages in the University, do not imply the ability to quickly find the right word in paper versions. Moreover, observations of students in the course of training showed that they are trying to find a ready-made translation in the dictionary, that is, the way the translator does it. Often there are cases when the student tries to see in the dictionary exactly the form of the word that is in the text, without bringing it to the initial (Part I and II, the plural of a noun, non-personal forms of a verb, etc.). If a word has several meanings, then the problem is often unsolvable. Finding the right meaning of a word and transforming it into a translation of the information given in the text becomes an impossible task. At the same time, students form a false understanding that dictionaries are useless, work with them is slow and the path to achieve the goal is very long. It is a very difficult task for a teacher to convince students that working with a dictionary can have a very good effect in the future when learning a foreign language.

Searching for a word in a dictionary forms a goal to achieve by matching all the meanings of words in a sentence according to the General idea of the text with their grammatical relationships. An electronic translator deprives a person of the process of analyzing a sentence, thinking about and identifying the necessary grammatical connections, comparing them with the meanings of words, and thus makes the study of the necessary sections of the language useless. If you study the rule and do not apply it in practice, it will not remain in memory, will lose its practical implementation and will not be applied in practice in the future, which will provoke errors and misunderstandings.

When we flip through a paper dictionary in search of the necessary words, we involuntarily pay attention to other dictionary entries that are also involuntarily fixed in our memory and can suddenly "pop up" in certain situations. Also, when we find the right word, for the correct translation of it in the text, we need to study all the meanings and examples presented to it. Thus, we understand its meaning more deeply. By translating a word using a dictionary in one sentence, we prepare the groundwork to translate it with less effort in another context. 


\section{Conclusion}

To solve the above issues, it is advisable to develop a textbook that would briefly list and describe the recommendations that help graduate students prepare for the exam. The ways of its distribution should be universal, namely as a traditional paper version, and in the form of a file that can be opened in an e-book, smartphone, or tablet. The file can be distributed in various ways, both by providing free download, and via email and social networks [5].

Organization of classes in the remote form

Today, distance learning is gaining popularity at almost all stages. It can be organized on the basis of specialized platforms such as Adobe Connect, Backboard Learn, Moodle, or using a wide range of social networks. Information and communication technologies make it possible to get an education at a distance from the educational institution and at a more convenient time.

The University itself, by organizing the process of distance learning, increases the number of people who want to get an education without the cost of equipping the training areas and purchasing equipment (classrooms, furniture, projectors, computers, etc.). Moreover, as the number of students increases, more study hours appear, which leads to higher salaries and the retention / increase of lecturers' jobs.

Distance learning is especially useful for graduate students. They are more conscious and responsible about their studies, and they have a clearer goal to achieve. But, as mentioned above, their employment and marital status limit their ability to attend classroom classes in person. Given the fact that universities are mostly located in large cities, and postgraduate classes are organized mainly in the evening (when the streets of the city peak traffic load, and often you need to find out just one or two questions, and most of the training material is in principle clear), the choice in favor of the distance form is obvious. Of course, distance learning has a number of disadvantages, but the development of technologies is so fast, and the experience of conducting online classes has already been accumulated sufficiently large that these disadvantages are easily leveled by certain technical techniques.

In general, the quality of training in such an organization of training does not decrease, but due to the redistribution of efforts by both the University and graduate students becomes more effective.

The basis for the organization of distance learning should be an electronic textbook, namely a resource that would meet the needs of all students with different levels of basic knowledge, namely:

- stages of understanding and translating a sentence (translation technique);

- recommendations for working with the dictionary;

- general grammar information with the ability to go to more detailed information (for example, "multi-functional verbs" is a general topic, and "have verb" is a more detailed grammar section for those students who have a knowledge gap);

- lexical minimum for specialties and areas of study in this academic group.

The textbook should be located on the Internet and have free round-the-clock access from any device, such as a personal computer, smartphone, tablet, etc. It is intended to unite a multi-level audience, where each of the trainees chooses the stages of the course, follows their own path at the speed that they consider acceptable for themselves and eventually strive to achieve a common goal.

In addition to the e-textbook, it should be possible to conduct video classes, demonstrate presentations, use the feedback form, exchange and store files, and access the results scale of classes. Our observations of students at different stages (undergraduate, graduate, and postgraduate) have shown that the results scale is an effective incentive to promote students in their studies, especially if these results are compared with other participants in an academic group, course, or even University. 
Experience with distance learning technologies has shown that this form of training is also convenient for the lecturer. Internet mobility today is at a high technological level. The high speed of unlimited mobile plans at a low price, the development of Wi- Fi networks and a variety of applications for communication between people make it possible to give individual and group consultations almost anywhere and at any time.

Combined model of organization of classes-classroom and distance learning.

Given the fact that despite the development of distance learning technology, not all universities are ready to accept it today. Even within one University, there are adherents of one or another form of education. However, it is possible to use the positive aspects of the models considered and combine them, thereby expanding the opportunities for training and improving the quality of training.

Let's take the example that a student is late for class. Once in the classroom, he needs to understand the essence of what is happening, enter the rhythm of the class, i.e. it will take some more training time. The lecturer will also need to distract himself, help this student by repeating, albeit briefly, the material that was presented at the beginning of the lesson. The situation is aggravated if a student misses a class. Thus, he is completely out of rhythm and he needs to restore this gap either on his own, or with the help of a teacher at the expense of classroom hours, which are already insufficient. This problem is easily solved if the classroom session was broadcast via a webinar. Today, there are many electronic platforms that allow you to organize a broadcast. They can be either paid, specialized (Adobe Connect, Blackboard Learn, etc.), or free (VK Live, YouTube, etc.). If a student is late or misses a class, he or she can connect to it via the mobile app. We are now seeing how people communicate through mobile apps. This happens everywhere. The same technologies are used in the training process without significant costs and even for free. If the lesson is recorded on video and given free access to it, then the opportunity for the graduate student to stay up to date with educational events becomes even greater.

So, by choosing a particular form of education, as well as their combination, we have made significant progress in teaching a foreign language in graduate school. Through electronic means, the development of a structured training course, students are able to receive a full course even in employment.

\section{References}

1. B.G. Ananyev, To the Psychophysiology of Student Age. Modern Psychological and Pedagogical Problems of Higher Education, 3-15 (1974)

2. B.M. Bim-Bad, Pedagogical Encyclopedic Dictionary, 192-193 (2002)

3. Federal Law About Education in the Russian Federation, N 273-FL, Retrieved from http://zakon-ob-obrazovanii.ru/ (accessed 03.08.2019), (dated December 29, 2012 with changes of 2019)

4. Great Soviet Encyclopedia, BSE, Retrieved from http://vslovare.info/slovo/bolshoijjentziklopedicheskiij-slovar/vzaimodeijstvie/152713 (accessed 28.02.2019) (2012)

5. G.M. Kodzhaspirova, Pedagogical Dictionary, (Moscow, Academy Publishing Center, 2005)

6. S.A. Lebedev, Philosophy of Science (2006)

7. National Doctrine of Education in the Russian Federation, Retrieved from http://sinncom.ru/content/reforma/index5.htm (accessed 03.08.2019)

8. I.A. Zimnyaya, Pedagogical psychology (Moscow, Logos, 2000) 
9. N. Davitishvili, Cross-Cultural Awareness and Teaching English as a Second Language in the Context of Globalization, Sino-US English Teaching, 14 (9), 549-558, DOI:10.17265/1539-8072/2017.09.003 (2017)

10. Intercultural Communication Diary. European Context, Key Concepts and Theoretical Foundations, Retrieved from http://www.coe.int/t/dg4/autobiography/Source/AIE_ru/ AIE_context_concepts_and_theories_ru.pdf (accessed 28.02.2019)

11. V.N. Karpenko, Formation of Experience of Intercultural Interaction among Future Specialists in the Socio-Cultural Sphere, Retrieved from http://www.dissercat.com/content/formirovanie-opyta-mezhkulturnogovzaimodeistviya-u-budushchikh-spetsialistov-sotsiokulturno\#ixzz5h0pMk3MA. (accessed 03.03.2019)

12. G.M. Kodzhaspirova, Pedagogical Dictionary (Moscow, Academy Publishing Center 2005)

13. O.K. Kozlitina, Pedagogical Support as a Condition for Students to Overcome Difficulties in Intercultural Iinteraction: on the Basis of Classes in a Foreign Language at University, Retrieved from http://www.dissercat.com/content/pedagogicheskayapodderzhka-kak-uslovie-preodoleniya-studentami-zatrudnenii-v-mezhkulturnom\#ixzz5h0qLSa63 (accessed 28.02.2019)

14. Yu.A. Romanov, T.A. Snegurova, Intercultural communication and teaching Russian to international students at language summer courses, Integration of Education, 21 (3), 371384, Retrieved from https://cyberleninka.ru/article/n/ intercultural-communication-andteaching-russian-to-international-students-at-language-summer-courses (accessed 05.08.2019). DOI: 10.15507/1991-9468.088.021.201703.371-384 (2017)

15. N.V. Polikasheva, Designing a System of Multicultural Education in Institutions of Additional Education of Children (Moscow, 2012) 